\title{
Insuring California Earthquakes and the Role for Catastrophe Bonds*
}

\author{
Jose S. Penalva Zuasti \\ Universitat Pompeu Fabra
}

February 20, 2001

\begin{abstract}
The 1994 Northridge earthquake sent ripples to insurance companies everywhere. This was one in a series of natural disasters such as Hurricane Andrew which together with the problems in Lloyd's of London have insurance companies running for cover. This paper presents a calibration of the U.S. economy in a model with financial markets for insurance derivatives that suggests the U.S. econommy can deal with the damage of natural catastrophe far better than one might think.
\end{abstract}

JEL: D58, G12, G22

Keywords: Catastrophe bonds, earthquake insurance, calibration, survival analysis

${ }^{*}$ This is a version of Chapter 5 of my PhD Thesis: Penalva[1997a]. 


\section{Introduction}

On January 17, 1994 an earthquake of magnitude 6.7 hit Northridge, a residential neighborhood in the Northern Los Angeles basin. The earthquake was followed by a long sequence of smaller quakes, or aftershocks, of smaller magnitudes in Northridge and surrounding areas. According to the US Geological Survey (USGS) ${ }^{1}$ sixty people were killed, more than 7,000 injured, 20,000 were left homeless and more than 40,000 buildings damaged in Los Angeles, Ventura, Orange, and San Bernardino Counties. Estimates of damage are between 13 and 20 billion U.S. dollars.

The reaction of insurance companies was such that a new institution was created: the California Earthquake Authority (CEA). The reason ${ }^{2}$ the CEA gives for its creation is that it was necessary in order to avoid debilitating the homeowners' insurance market and to keep earthquake insurance available at affordable prices. This is because California law requires insurers to offer earthquake insurance with every homeowners policy. After having to absorb big payments from the Northridge earthquake, many companies considered withdrawing from the California homeowners' insurance market altogether.

The Northridge earthquake, along with Hurricane Andrew, has triggered widespread concern among insurance companies that reinsurers may not be able to provide the kind of coverage needed to pay for damage from a major natural catastrophe. These concerns have accelerated interest in applying finance to insurance markets. In particular, since December 1996 insurance companies have started to issue a new kind of security: catastrophe bonds. The bonds promise to pay three or four percentage points more than comparable corporate bonds but there is a catch: if within a year the catastrophe on which the bond is written (for example, there is an earthquake in the Northeastern part of the U.S.) causes a sufficiently large number of claims on the issuing company, the holders of the bond lose part or all of the principal ${ }^{3}$.

In this paper I will use a special framework developed in Penalva [1997a,

\footnotetext{
${ }^{1}$ This information was obtained from the USGS web site at: http://gldss7.cr.usgs.gov/neis/eqlists/94.lis,

on June 7, 1997.

${ }^{2}$ This information was retrieved from CEA's website on June 7, 1997 at: http://www.insurance.ca.gov/PRS/CEAQ\&A.html

${ }^{3}$ See the article in The New York Times by Joseph H. Treater on August 6, 1997.
} 
1997b] to make an economic model of the California economy and its exposure to earthquakes. The model suggests that the possible damage from a major earthquake would be substantial but small relative to U.S. GNP. It also suggests that the risk from such a catastrophe can be optimally allocated through reasonably priced insurance contracts and well-functioning financial markets in insurance derivatives, such as catastrophe bonds.

The purpose of this exercise is to see how a perfectly-functioning competitive insurance market would deal with the damage caused by a major earthquake to California real estate, compare that with the proposals of the CEA, and study the role that earthquake bonds play in allowing for the spreading of this risk. The model focuses exclusively on catastrophic damage to residential real estate. As we will see, the expected damage and cost of insurance for "the Big One" are greatly exaggerated, and catastrophe bonds offer a substantial excess return.

This paper is divided into four main sections. In the first section I will go into detail as to what an earthquake is, how it is measured, and what kind of damage it causes. In the second section I will outlined the model and describe the calibration used to estimate the parameters of the model. In the third section I will describe the results of the calibration for the ArrowDebreu economy, and in the fourth section I will look at what these results tell us about the competitive prices for insurance contracts and catastrophe bonds.

\section{Earthquakes and Earthquake Damage}

The first step of the analysis takes us into the realm of geophysics. Before talking about the economic consequences of earthquakes, one needs to understand somewhat what earthquakes are, how they are measured, and the kind of damage they can create. There is a somewhat warped perception of the kind of damage to expect from an earthquake in California, even a major one, so it is helpful to understand some of the facts.

An earthquake is rapid ground shaking (ground motion) and is generally due to movement of tectonic plates, the eruption of volcanos (which is not necessarily distinct from movement in tectonic plates), the collapse of mines or underground caverns, or to explosions (usually associated to nuclear testing underground).

Earthquake risk in California is due primarily to the first cause: the movement of tectonic plates. Tectonic plates are huge masses of rock that form the Earth's crust (lithosphere). There are relatively few of them and 
their movement is measured in centimeters (or inches) per year. The movement of these plates is the main cause for the geological shape of continents and their landscape, specially mountains. Three tectonic plates meet in the Northern part of the state. The primary cause for concern in California is the fault system associated with the two main plates: the North American plate and the Pacific plate. The 'frontier' between two plates is not neatly demarcated by a single line but by a band, tens of kilometers wide, which I will call the fault system, and which mainly affects the California coast South of San Francisco. Within this 'frontier' there are long cracks on the rock layers, which I will refer to as faults or fault lines. These are displayed in Figure 1.

If the pressure generated by plate movement is not sufficient to move the bodies of rock that make up the fault system, stress will accumulate in those rocks. Stress accumulates until it exceeds the elastic capacity of the rock and, as the rock gives way to the accumulated strain, energy is released in the form of heat and seismic energy. Heat, which takes up ninety per cent or more of all the released energy causes no damage to people or property. Seismic energy, on the other hand, makes the ground shake. Seismic energy travels as waves, and there are three kinds:

1. Primary waves are the fastest waves generated by an earthquake. Traveling through water as well as solid matter, they generate a push-pull motion which, when reaching the surface, feels like a brief, strong shock or jolt.

2. Secondary waves, also quite fast, travel only through land. This type of wave is felt more strongly than the primary waves and generates horizontal and vertical ground movement that can be quite damaging to buildings. As it moves from solid rock to softer soil the wave is felt for a longer period of time and increases in amplitude, generating more vigorous shaking.

3. Surface waves travel along the surface of the lithosphere and are only distinguishable in the immediate area of the shock. One variety of surface waves, the Love wave, generates side-to-side motion similar to that generated by secondary waves but without the vertical displacement. They are particularly damaging to building structures and foundations. The second variety, the Raleigh wave, generate an ocean wave type of motion particularly damaging to the superstructures of tall buildings. 
The effect of the waves is affected by a number of factors. The geologic properties of the land the waves travel through affects their strength and speed, and it can transform them from one type to another. Also, the depth of the epicenter matters. Shallow earthquakes (at a depth of less than 15 miles) account for ninety per cent of tectonic earthquakes in the world but only seventy-five percent of total energy released, and are more common around fault lines, like most California earthquakes. But even for shallow earthquakes differences in depth increase the difficulty of estimating the strength and direction of ground shaking on the surface. An additional factor is the tendency of earthquakes to cluster (geographically and over time). As earthquakes are generated by the release of accumulated strain an earthquake in one place is a signal that there is stress accumulated there. The waves generated by one earthquake can trigger the release of energy in nearby areas. Hence, an earthquake is not just a single event at a unique location but a cluster of ground motions in space-time: the so-called foreshocks and aftershocks. The earthquake is named after the location of the largest release of energy in that cluster, as with the Northridge earthquake (in addition to the Northridge quake there were over 5,000 measurable aftershocks within the subsequent 30 days $^{4}$; foreshocks are much more rare and difficult to classify).

\subsection{Quake Measurement}

Given the complex nature of earthquakes, it is hard to imagine how one number could adequately describe them, and naturally there isn't. There are measures of acceleration, the amount of energy released, moment magnitude, felt effects, etc. Energy released is considered the most appropriate magnitude describing an earthquake as it measures the physical effect that defines it. The two main measures of energy released are described by the acronyms $\mathrm{Mw}$ and Mo. Both $\mathrm{Mw}$ and Mo measure energy released in the same way (they are like Fahrenheit and Centigrades). Mw is scaled so that measurements in $\mathrm{Mw}$ simulate those of the more familiar scale, ML, the famous Richter magnitude. The Richter scale measures a different effect of earthquakes, the amplitude of the largest waves generated by the earthquake on the surface. Wave amplitude measures do not accurately measure released energy, yet they are useful measures of the physical effects of an earthquake as felt on the surface, and in practical terms what matters is the amount of shaking generated.

\footnotetext{
${ }^{4}$ Iacopi $[1996]$
} 
Acceleration is measured to determine the strength of shaking, a good measure of potential damage as it is shaking that mainly affects the integrity of a structure. Together with acceleration, the duration of shaking and mean velocity give a good idea of the stress produced on structures.

Finally, there is a qualitative description of the amount of physical damage generated by an earthquake, the Modified Mercalli Intensity scale (MMI). This measure is determined from interviews with people at different locations in the areas surrounding the earthquake and from observations of the physical destruction generated. A copy of the scale is reproduced in Appendix 8. A large earthquake in the middle of the desert would generate a much lower MMI than a moderate earthquake in the middle of a densely populated area. 


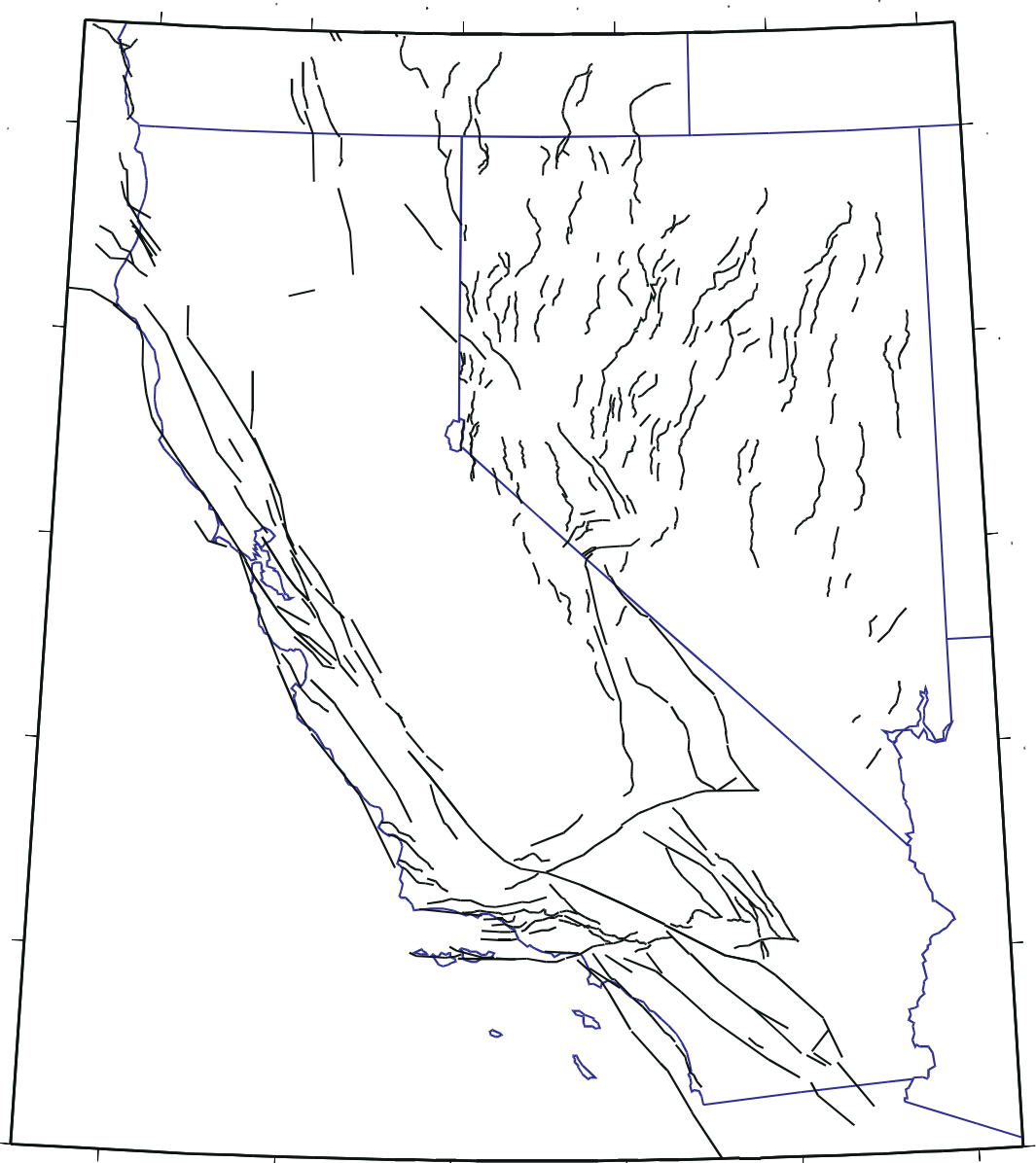

Figure 1: Main Faults in California. 


\subsection{Quake Damage}

The sudden release of energy in the form of heat and seismic energy has economic consequences because they cause differential ground settlement, land and mud slides, soil liquefaction, ground lurching, avalanches, tsunamis and seiches, ground displacement along the fault, and last, but by no means least, ground shaking. These cause dams to overflow and/or break, structures to collapse, objects to fall, pipes to burst with subsequent fires and toxic contamination, etc. These generate loss of life, injuries, and the destruction of property and infrastructure.

I am going to concentrate this analysis on major damage to residential structures, where by major damage I mean the collapse or prolonged closure of a structure due to the need for major structural reconstruction. The main cause of major damage to residential structures is due to ground displacement, at and around the fault, and ground shaking. The extent of damage mainly depends on the magnitude of the earthquake, the duration of motion and proximity to the epicenter.

There are two additional factors that are particularly important: the geologic foundation, and the structural design and construction quality of the structure. Softer soils can increase the intensity of shaking and prolong its duration. Unstable soils, such as artificially engineered landfills (of sand, quarry ruble, or even garbage) and heavy concentrations of mud, are particularly sensitive to ground shaking.

The importance of structural design and construction quality is obvious when one compares the damage caused by earthquakes in the Western U.S. or Japan in the last twenty years with that caused by similar, even milder earthquakes in the U.S. at the end of the last century or more recently in developing nations such as Iran, Peru or China. The most important factors determining the sensitivity of a structure to ground shaking is the solidity of its foundations (and being bolted to them), and the materials and design of the structure itself. Ordinary unreinforced masonry structures (common among developing nations) are particularly vulnerable to ground motion because of their heavy mass and low resistance to lateral forces.

For damage in California, the main two factors determining potential damage are magnitude and location. A moderately large to large earthquake with an epicenter close to a highly densely populated area would generate the kinds of widespread destruction that give insurance companies much concern. In terms of the model, I will concentrate on very large, "catastrophic" earthquakes, such as the 1906 San Francisco earthquake, with a magnitude of M7.5+ (the famous "BIG ONE"). 
A model of the economic consequences of earthquakes on California's residential real estate will need to take into account all the different aspects of earthquakes and combine them with knowledge of the status of California homes, their structure and their location. In the following sections I will embed this information within a very simple model of the U.S. economy to analyze the importance of the damage generated by earthquakes relative to the economy as a whole, and to see how a perfectly-functioning insurance market will deal with it.

\section{The Model}

The model I present here fits within the general class of calibration models. Such models have been extensively used in the macroeconomic literature and are regarded as a useful exercise in testing and understanding the contributions of different theoretical models.

The economy is a pure exchange economy with perishable endowments available at discrete intervals and perfectly functioning, continuously trading security markets.

Agents: Agents are indexed by $i \in I$ and represent households. They all have the same preferences and priors but differ in the following manner:

- Endowments $\left(w_{i}\right)$ : they have a high or a low endowment

- Location: they live in an area prone to large damaging earthquakes or not. Those who live in an area prone to large damaging earthquakes live either in the Bay area or the Los Angeles basin.

- Building structure: those at risk can live in a rich expensive onefamily home, an average one-family home, a multi-family home, or an apartment building.

- Age of building structure: those at risk can live in a pre-1970 or a post-1970 building.

A household is described by its type, which is combination of the above factors. Agents live for 70 years (280 quarters) and evaluate their consumption streams using the following VonNeuman-Morgenstern utility function

(1) $\quad U(x)=E\left[\sum_{t=0}^{280} \beta^{t} \frac{x(t)^{1-\rho}}{1-\rho}\right]$ 
Uncertainty: The fundamental source of uncertainty, the earthquakes, is modeled by a point process, $N$. The random variable $N(t)$ describes the number of earthquakes that have occurred up to and including time $t \in \mathcal{T}:=[0, T]$.

(2) $\quad N$ generates a filtration $\mathbf{F}:=\left(\mathcal{F}_{t}\right)_{t \in \mathcal{T}}$

Commodities: Economic activity takes place on a hybrid time scale. Endowments and consumption are realized on a discrete time set given by $T:=$ $\{0,1, \ldots, 280\}$, as in the standard discrete time macroeconomic models, and security trading takes place continuously, on the time set $\mathcal{T}:=[0,280]$.

(3a) Consumption and endowments are realized on the time set $T:=$ $\{0,1, \ldots, 280\}$. Trading takes place continuously, on the time set $\mathcal{T}:=$ $[0,280]$.

(3b) There is a single perishable commodity available for consumption at every date-event:

$$
L:=L_{\infty}\left(\Omega, \mathcal{F}, P,\left.\mathbf{F}\right|_{T}\right)^{281},
$$

where $\left.\mathbf{F}\right|_{T}$ is the restriction of $\mathbf{F}$ to the discrete time set $T$. In this model, preferences and endowments only care about the number of earthquakes that have occurred at consumption dates up to and including time $t$, but, the exact timing of the last earthquake affects the probability of future ones. This means that commodity prices and allocations will be independent of the exact timing of the jumps, but trades and security prices will depend on them.

Consumption and endowments are aggregated over time, more specifically over quarters (three months). The role played by homes in this simplistic model is highly stylized: housing services are regarded as a part of the agent's endowment of the single available commodity; if there is an earthquake, the loss of a home is represented by a reduction in the agent's endowment over a period of time in the future.

Security Markets: Security trading takes place continuously. Agents are assumed to receive information continuously, and use that information to adjust their wealth holdings among securities.

(4) The securities available for trading are: catastrophe bonds: one for the Los Angeles area and one for the San Francisco area, insurance contracts on the agent's home, and a riskless bond. 


\subsection{The Parameters}

I have used data from a number of different sources to calibrate different aspects of the model. The main sources are the 1990 U.S. Census and the USGS either from data provided by them directly or via their sites on the Internet.

\subsubsection{Agents}

Agents are defined as households. In the census, the number of occupied housing units is the same as the number of households, so I let each agent represent one household and one housing unit. According to the census there were 92 million households in the United States in 1990, 10.4 million in California.

There are 18 types: 'rich' or 'poor' who either do not live in California or those that do but are not at risk (RN, PN), and 16 types who live in California and are at risk as described in Table 1

Table 1: Acronyms for different types of households in California at risk

\begin{tabular}{c|cc}
\multicolumn{3}{c}{ Rich in one-family homes } \\
& post-1970 & pre-1970 \\
\hline In L.A. & RA0LA & RA1LA \\
In S.F. & RA0SF & RA1SF
\end{tabular}

Poor in multi-family homes

\begin{tabular}{c|cc} 
& post-1970 & pre-1970 \\
\hline In L.A. & PB0LA & PB1LA \\
In S.F. & PB0SF & PB1SF
\end{tabular}

Poor in one-family homes

\begin{tabular}{c|cc} 
& post-1970 & pre-1970 \\
\hline In L.A. & PA0LA & PA1LA \\
In S.F. & PA0SF & PA1SF
\end{tabular}

\section{Poor in apartment building}

\begin{tabular}{c|cc} 
& post-1970 & pre-1970 \\
\hline In L.A. & PC0LA & PC1LA \\
In S.F. & PC0SF & PC1SF
\end{tabular}

I have classified households into 'at risk' and 'not at risk' of earthquakes by geographically superimposing USGS grid data on expected maximum peak acceleration (with 10 per cent probability of excedance in 50 years) on California county subdivisions, to obtain the average maximum peak acceleration per county subdivision. The grid data are data points on a square grid, and California county subdivisions are entities created by the U.S. Census to report aggregate subcounty statistics. In California, the county subdivisions are called Census County Subdivisions (CCSs) which are the equivalent of Minor Civil Divisions (MCDs) in other states. There 
are 386 CCSs and 58 counties in California ${ }^{5}$.

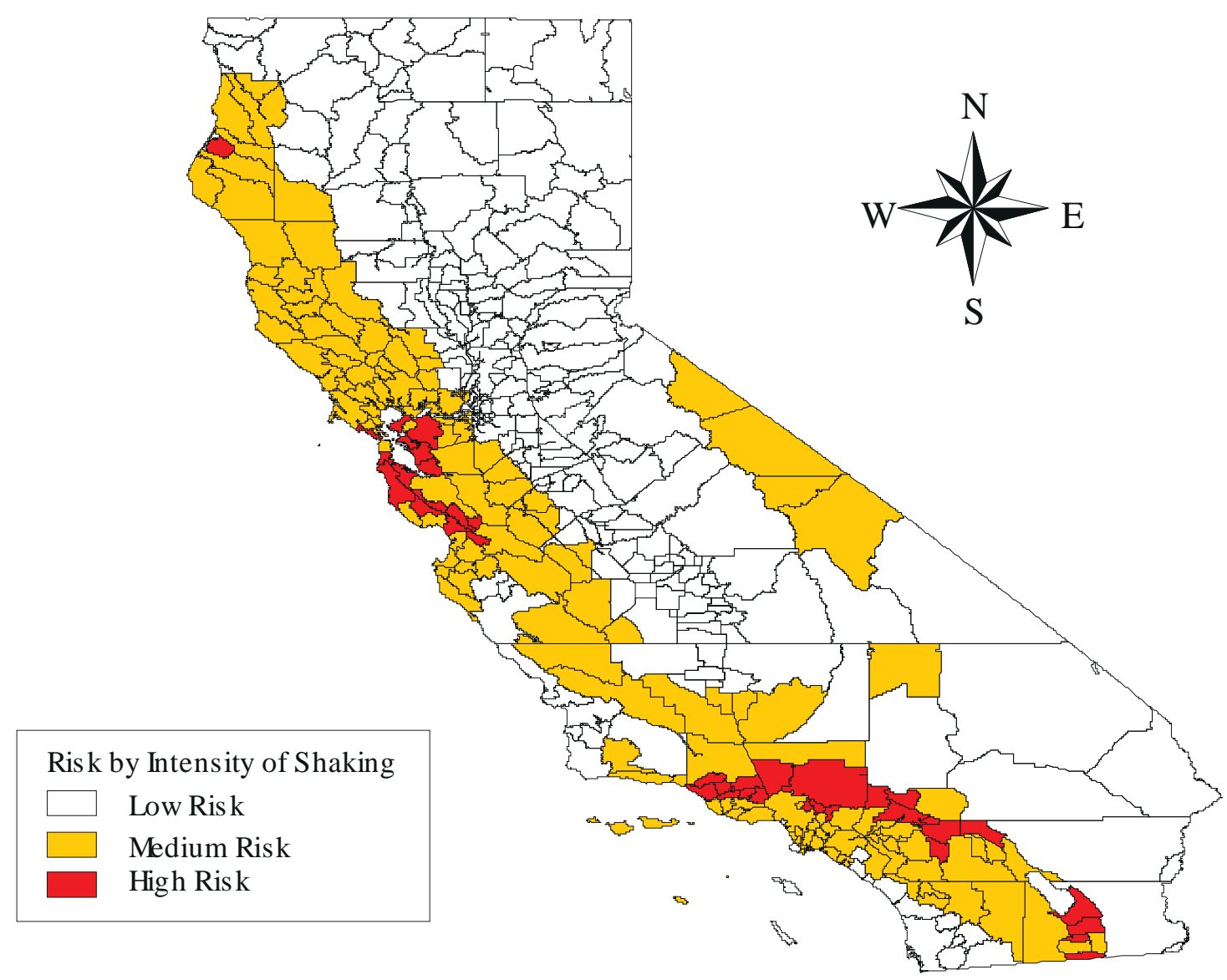

Figure 2: California Subdivisions According to Risk of Major Earthquake.

Each county subdivision has then been classified as high risk, medium risk and low risk (according to whether the average maximum peak acceleration was greater than $0.65 \mathrm{~g}$, between $0.35 \mathrm{~g}$ and $0.65 \mathrm{~g}$, or less than $0.35 \mathrm{~g}$ ). This classification is displayed in Figure 2. The cutoff for low risk areas is $0.35 \mathrm{~g}$ because the kind of firm ground shaking generated by moderate earthquakes a few tens of kilometers away is between 0.05 and $0.35 \mathrm{~g}$ and is unlikely to generate any substantial damage. The choice of 0.65 to separate

\footnotetext{
${ }^{5}$ For more details on CCSs see the 1990 Census of Population and Housing: Guide. I will generally refer to CCSs as county subdivisions.
} 
medium from high risk areas is chosen because it turns out to distinguish those that are closer to a major fault system from the others. The particular choice, 0.65, mainly affects Ventura (0.69) and Upper San Gabriel (0.66). In the Bay area, Oakland, Freemont and Hayward have 0.73, 0.73 and 0.75 g's respectively. The San Francisco division has $0.54 \mathrm{~g}$, the Los Angeles division $0.56 \mathrm{~g}$, and the Pasadena division $0.71 \mathrm{~g}$. In terms of probability of being close to an epicenter, anything between 0.6 and $0.7 \mathrm{~g}$ seems to lead to the right classification.

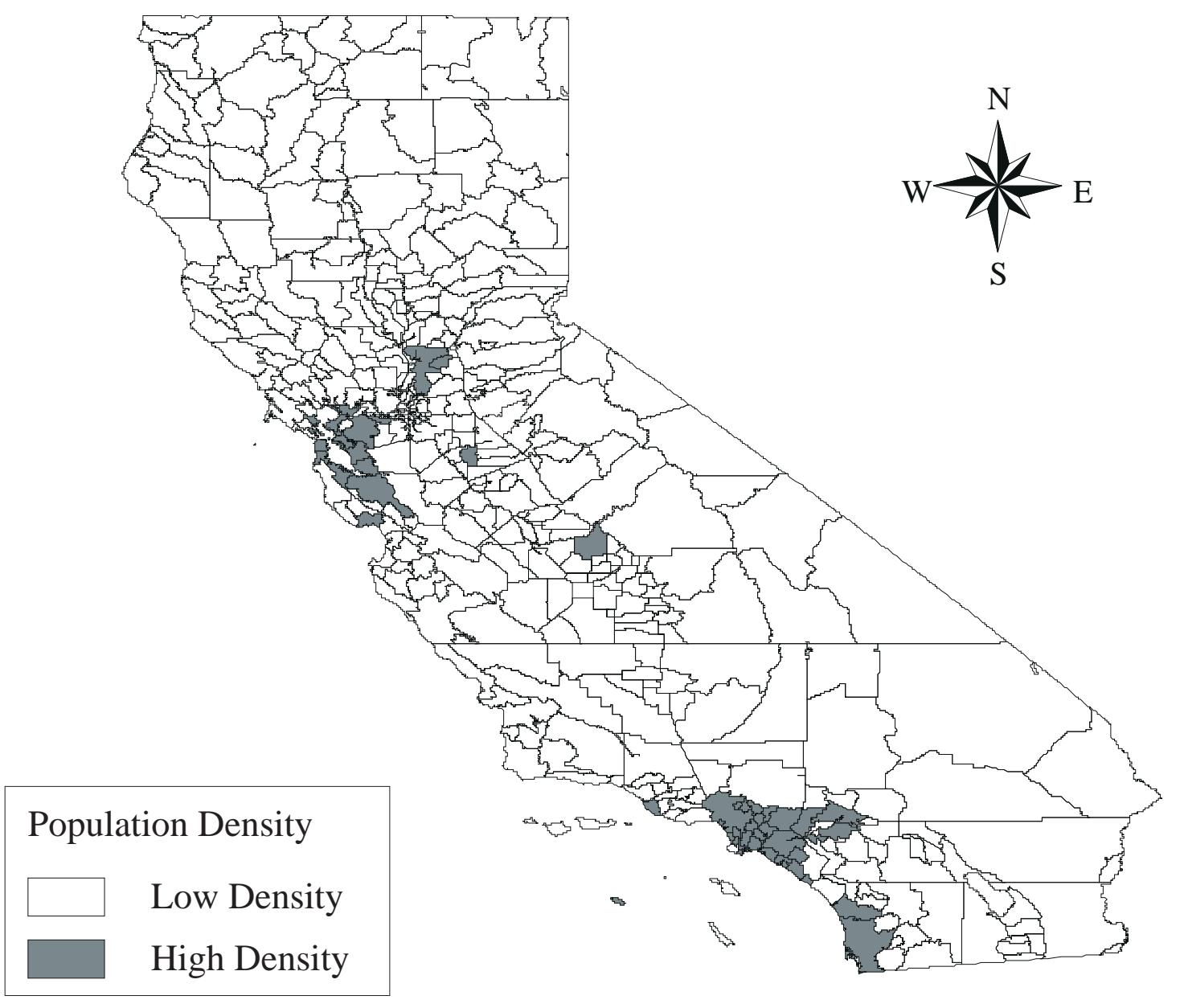

Figure 3: Highly Densely Populated California Subdivisions. 
Furthermore, as I am interested in modeling the economic risks associated with highly damaging earthquakes, I have chosen to restrict the counties at risk to those that are densely populated. Earthquakes in a lightly populated area, such as the 1992 Landers M7.5 and Big Bear ${ }^{6}$, are ignored in this model. I have chosen to classify divisions into densely and sparsely populated by looking at the number of households per square mile. Divisions with 500 or more households per square mile are classified as being densely populated and can be seen in Figure 3. Densely populated divisions include all the obvious ones, San Francisco $(6,548)$, Oakland (2,547), Los Angeles $(2,608)$, Pasadena $(1,768)$, etc. It excludes some counties that are 'at risk' but are not populated densely enough such as Santa Barbara division (165), Palos Verdes division (210), Sea-side Monterey (477), Thousand-Oaks (476) and Ventura (300). Putting these together, I have classified households as 'at risk' if they are located in a subdivision which is densely populated and at medium or high risk of significant shaking, such divisions I call California at Risk Divisions (CARDs) and they all happen to be either in the Bay area or in the Los Angeles basin (hence the geographical classification of homes). In total, there are 5,876,707 (57\% of California) households in California at risk divisions (CARDs), and 1,400,706 of them in high risk divisions (13\% of California, $24 \%$ of at risk). The precise map of these CARDs are depicted in Figures 4 (for those in the Los Angeles area) and 5 (for those in the San Francisco Bay Area).

The classification into rich and poor households is somewhat artificial due to the special nature of California households. Land prices are particularly high in California and home ownership is well below the national average ( $51 \%$ vs. $64 \%$ ). Hence I will assume that homes are owned primarily by the rich. Following this logic I have taken all households who own a home valued at $\$ 150,000$ or more in California to be the rich households. These represent $30 \%$ of all California households and $54 \%$ of owner-occupied housing in California. Taking this proportion as a constant and using census data on household income in 1989, the $30 \%$ cutoff implies household income above $\$ 50,000-55,000$ for the divisions at risk and $\$ 40,000-42,500$ for the rest of the US (including the not at risk California divisions). The average household income is $\$ 42,200$ and $\$ 32,500$ for California at risk divisions (CARDs) and for the rest of the US, respectively ${ }^{7}$. If we fix the incomes of the rich households at $\$ 70,000$ and $\$ 50,000$ this implies incomes

\footnotetext{
${ }^{6}$ The Big Bear earthquake has been classified as a foreshock of the Landers earthquake.

${ }^{7}$ This average is not the average over all households but over households with income less than $\$ 150,000$ - this is to eliminate the bias from households with extremely large incomes.
} 


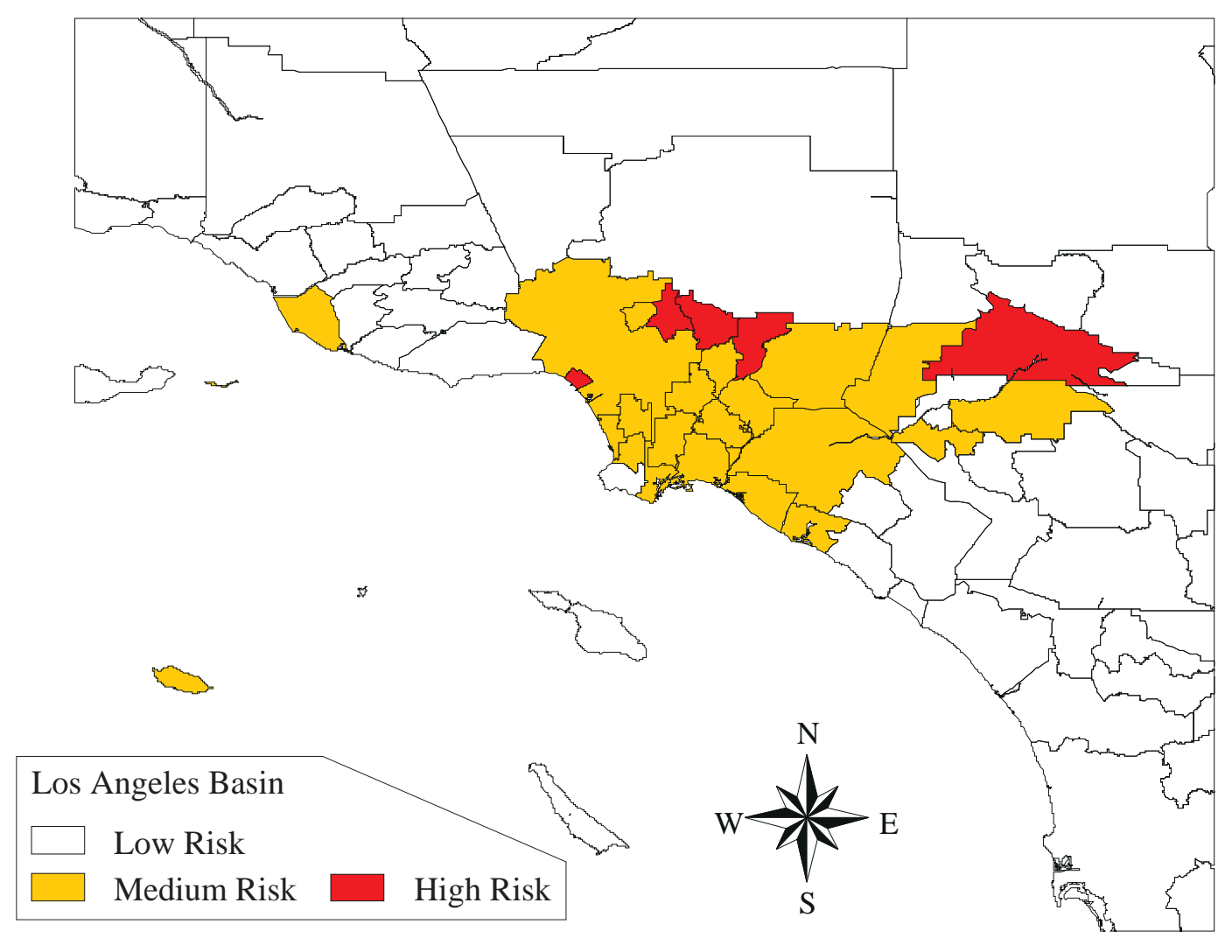

Figure 4: CARDs in the Los Angeles Area.

for the poorer households of approximately $\$ 30,000$ and $\$ 25,000$ for CARDs and non-CARDs respectively. I use these as the calibrated endowments (appropriately adjusted to the quarterly structure of the simulation).

Preference parameters are calibrated using generally acceptable values: 0.99 as the value of the discount parameter, $\beta$, and $1 / 2$ as the value of the risk aversion parameter, $\rho^{8}$.

\footnotetext{
${ }^{8}$ Cooley and Prescott, in Economic Growth and Business Cycles (in Cooley [1995]) use a quarterly value of 0.987 for the discount parameter, and a value of $\rho=1$, logarithmic preferences. The results in the simulation are very robust to variations in these parameters.
} 


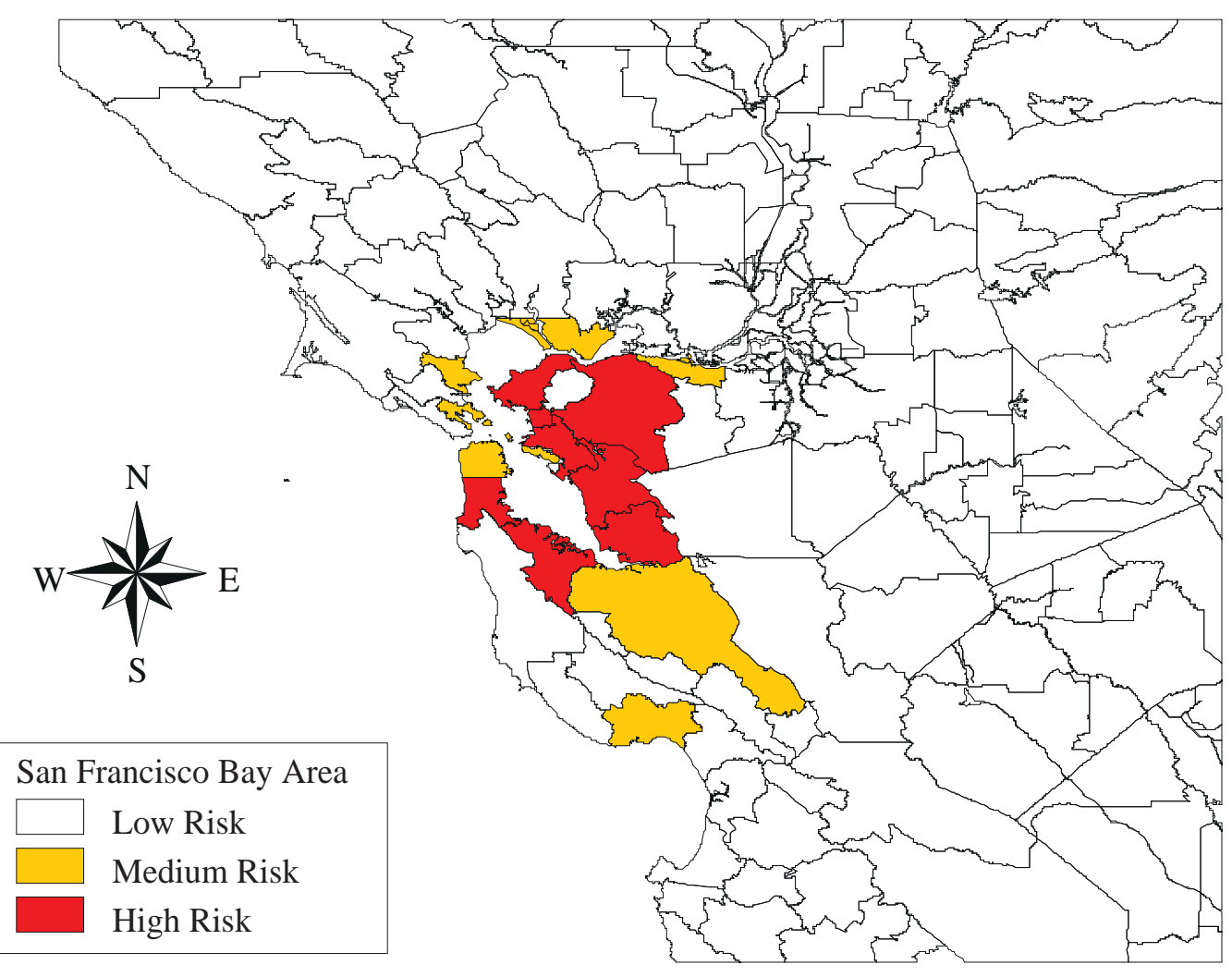

Figure 5: CARDs in the San Francisco Bay Area.

\subsubsection{Quakes}

As I have explained above, earthquakes are highly complex geological phenomena. Despite having a large quantity of research effort dedicated to studying and understanding earthquakes, little progress has been made in determining what are the relevant observable factors that precede and help predict earthquakes. The randomness in the relationship between factors that theoretically cause earthquakes and the occurrence of earthquakes (given the present state of knowledge) makes them natural candidates for statistical analysis. Unfortunately, precise, reliable and extensive measurement of earthquakes on the surface of the Earth has only been available for a few decades. Since 1946, the USGS has records for 481 earthquakes of magnitude 6 or greater (in the California fault system). Of these, 21 have 
been of magnitude $6.5+$ and 2 or M7.5+, very few for statistical analysis 9 .

The approach I have followed has been to try to find statistical regularity in the interarrival times for the $481 \mathrm{M} 6+$ earthquakes. The data is described, non-parametrically, in Table 2.

Table 2: $\log ($ Interarrival Times), 481 Observations

\begin{tabular}{|c|c|cc|cc|}
\hline $\begin{array}{c}\text { Survival Time } \\
\text { (logs) }\end{array}$ & $\begin{array}{c}\text { Survival Time } \\
\text { (Days) }\end{array}$ & Enter & Exited & Survival Rate & Hazard Rate \\
\hline $0.0-0.6$ & $1-2$ & 481 & 40 & 1.0000 & 0.1443 \\
$0.6-1.2$ & $2-4$ & 441 & 63 & 0.9168 & 0.2559 \\
$1.2-1.8$ & $4-7$ & 378 & 69 & 0.7859 & 0.3342 \\
$1.8-2.4$ & $7-12$ & 309 & 80 & 0.6424 & 0.4947 \\
$2.4-3.0$ & $12-21$ & 229 & 89 & 0.4761 & 0.8025 \\
$3.0-3.6$ & $21-37$ & 140 & 69 & 0.2911 & 1.0880 \\
$3.6-4.2$ & $37-67$ & 71 & 17 & 0.1476 & 0.4525 \\
$4.2-4.8$ & $67-122$ & 54 & 4 & 0.1123 & 0.1280 \\
$4.8-5.4$ & $122-222$ & 50 & 11 & 0.1040 & 0.4112 \\
$5.4-6.0$ & $222-405$ & 39 & 39 & 0.0811 & 3.3271 \\
\hline
\end{tabular}

Source: Author's tabulation of USGS data using LIMDEP.

I have also fitted a parametric model: a convex combination of two Weibull distributions on the interarrival times. The corresponding CDF is:

$$
F(t)=1-\alpha \exp ^{-\left(\lambda_{1} t\right)^{\gamma_{1}}}-(1-\alpha) \exp ^{-\left(\lambda_{2} t\right)^{\gamma_{2}}}
$$

The statistical model has no justification in geophysical terms but it fits the data quite well. The estimated parameters and the standard errors are given in Table 3

What the data and the parametric model describe is high and increasing initial hazard the first month after a M6.0+ earthquake, followed by a long period of relative inactivity (six to seven months) which comes to an end relatively quickly after the seventh month.

I have taken this statistical description and fit it to the less frequent M7.5 + class of earthquakes. I have done this by keeping the shape parameters, the $\gamma$ 's, and the relative weight of the two Weibulls, the $\alpha$, constant

\footnotetext{
${ }^{9}$ The interested reader will find a list of the major California earthquakes since 1900 in Appendix 7.1.
} 
Table 3: Parameter Estimates

\begin{tabular}{|c|cc|cc|}
\hline$\alpha$ & $\lambda_{1}$ & $\gamma_{1}$ & $\lambda_{2}$ & $\gamma_{2}$ \\
\hline 0.883576 & 1.11708 & 0.07874 & 4.14153 & 0.00393 \\
\hline (N/A) & $(0.04925)$ & $(0.00361)$ & $(0.27452)$ & $(0.00014)$ \\
\hline
\end{tabular}

Source: Author's estimation using LIMDEP.

and adjusting the scale parameters, the $\lambda$ 's, to match the mean arrival times of the larger earthquake as follows:

$$
F(t, c)=1-\alpha \exp ^{-c\left(\lambda_{1} t\right)^{\gamma_{1}}}-(1-\alpha) \exp ^{-c\left(\lambda_{2} t\right)^{\gamma_{2}}}
$$

The estimated value of $c$ is 0.000114 for a mean arrival rate of one earthquake every 100 years.

These values match the observed mean arrival time of these earthquakes. I have used the corresponding CDF to simulate the interarrival period along a number of paths over a 280 quarter (70 year) horizon. The hazard generated by this scaling, depicted in Figure 6, increases rapidly at first, until it peaks (at around 2,100 days, or about five and a half years). After that, the hazard quickly drops and only increases very slightly after 70 years.

The paths generated in this way simulate the occurrence of earthquakes along the California fault system. The geo-economic properties along the fault system are very varied as one goes form one subdivision to the next, and the economic effect of these quakes varies accordingly. As I have chosen to concentrate my attention on quakes in densely populated areas, I need to eliminate many of the quakes (those that occur in thinly populated areas). Correspondingly, I have filtered the paths to account for this by 'thinning' them using a binomial random variable, i.e., every time the simulation generates a quake, it also generates a $\{0,1\}$-valued random variable. If the random variable is a 1 , the quake is recorded and if it is a 0 the quake is ignored (deleted). I have used the proportion of land in the CARDs relative to the total surface area of the divisions with a medium to high risk of earthquakes as a filtering parameter. Unfortunately, as the CARDs only represent 8 per cent of the area at risk, this procedure generates paths with an average of one $6.5+$ damaging earthquake per 70 years ${ }^{10}$, which is strikingly different from the data: there have been four $6.5+$ quakes in relatively

\footnotetext{
${ }^{10} \mathrm{I}$ have used $6.5+$ earthquakes to calibrate the filtering parameter because the M7.5+ are too rare.
} 


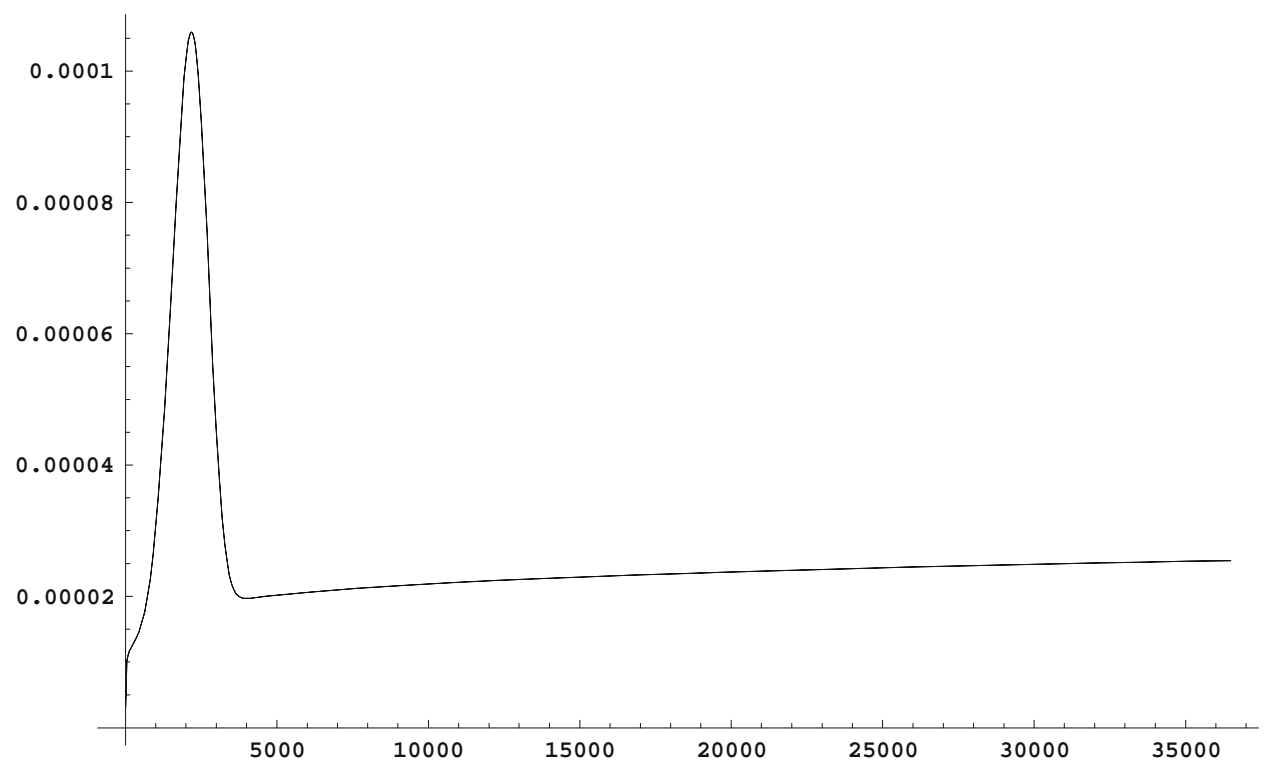

Figure 6: Estimated Hazard Function for M7.5+ earthquakes (time scale is in days).

densely populated areas over the past 70 years, namely the '94 Northridge, the '89 Loma Prieta, the '71 San Fernando and the '33 Long Beach earthquakes. This implies either that the last 70 years have seen an unusually high number of $6.5+$ earthquakes, or that the CARDs are more earthquake prone than the other divisions. Geophysicists would probably point out that the area occupied by the CARDs, especially those in the Bay area, is more prone to earthquakes than similar areas around other sections of the fault. In order to take this into account I have quadrupled the probability of a quake in a CARD from 8 per cent to 32 , leaving me with an average of just over 3.5 earthquakes of magnitude M6.5+, and 0.7 for the $7.5+$ quakes for the 70 year period (or 1 every 100 years) - quite reasonable estimates. These paths are the uncertainty primitives on which the rest of the model is built.

\subsubsection{Earthquake damage}

The calibration of earthquake damage is particularly tricky due to the rich variety of possibilities and factors that need to be taken into account. The two main sources of information in this section have been the EERI [1994] 
study: Expected Seismic Performance of Buildings, and the excerpts from the ABAG [1997] publication Earthquake and Housing Impacts at the site

http://www.abag.ca.gov/bayarea/eqmaps/shelpop/awaketoc.html.

EERI [1994] is primarily designed to describe the damage expected to occur to buildings under the 1991 Uniform Building Code (UBC) when shaken by various earthquakes. Tables 4 and 5 (taken from the report) describe the percentage of buildings expected in different damage states for various levels of shaking. They also provide a very useful relationship between earthquake magnitude, distance to the epicenter, and realized MMI intensity (a good measure of the extent of damage). Damage states describe the state of the building after the tremor.

Table 4: Percentage of Buildings Expected in Each Damage State for Various Shaking Intensities: Buildings Designed Under the 1991 Unified Building Code

\begin{tabular}{|c|c|c|c|c|c|c|c|}
\hline \multirow{2}{*}{\multicolumn{2}{|c|}{$\begin{array}{c}\text { Size of Earthquake } \\
\text { (Magnitude) }\end{array}$}} & \multirow{4}{*}{$\begin{array}{l}\text { Expected } \\
\text { MMI }\end{array}$} & \multicolumn{5}{|c|}{ Standardized Damage States } \\
\hline & & & \multirow{3}{*}{$\begin{array}{r}\text { A } \\
\text { None }\end{array}$} & \multirow{3}{*}{$\begin{array}{r}\text { B } \\
\text { Slight }\end{array}$} & \multirow{3}{*}{$\begin{array}{r}\mathrm{C} \\
\text { Moderate }\end{array}$} & \multirow{3}{*}{$\begin{array}{r}\mathrm{D} \\
\text { Extensive }\end{array}$} & \multirow{3}{*}{$\begin{array}{r}\mathrm{E} \\
\text { Complete }\end{array}$} \\
\hline $6.0-6.5$ & $7.5-8.0$ & & & & & & \\
\hline \multicolumn{2}{|c|}{ Distance to Fault } & & & & & & \\
\hline $30 \mathrm{mi}$ & $50 \mathrm{mi}$ & VII & $60-90$ & $10-40$ & $1-5$ & $<1$ & 0 \\
\hline $5 \mathrm{mi}$ & $40 \mathrm{mi}$ & $\overline{\text { VIII }}$ & $35-60$ & $35-45$ & $10-30$ & $<5$ & $\overline{<1}$ \\
\hline $1 \mathrm{mi}$ & $30 \mathrm{mi}$ & IX & $25-40$ & $25-40$ & $20-40$ & $3-10$ & $<2$ \\
\hline- & $3 \mathrm{mi}$ & $\mathrm{X}$ & $5-25$ & $5-25$ & $40-70$ & $\overline{10-30}$ & $<5$ \\
\hline
\end{tabular}

Source: Expected Seismic Performance of Buildings, EERI.

This is very useful information but it relates primarily to structures subject to the UBC which is not the average one family home; it is primarily useful to estimate damage to apartment buildings.

In order to understand the damage caused by an earthquake to the general housing stock, and to residential homes in particular, I have referred to the ABAG [1997] report. The ABAG report is conceived to estimate uninhabitable dwellings for future earthquakes affecting the San Francisco Bay Area. Uninhabitable is defined to mean unable to be occupied due to structural problems, which is a close approximation to damage states D and $\mathrm{E}$ (and maybe $\mathrm{C}$ ) in the EERI report. The ABAG report uses computer simulations to study different earthquake scenarios around the bay area and 
Table 5: Percentage of Buildings Expected in Each Damage State for Various Shaking Intensities: Buildings Unreinforced Masonry Rehabilitated Under the Unified Building Code

\begin{tabular}{|c|c|c|c|c|c|c|c|}
\hline \multirow{2}{*}{\multicolumn{2}{|c|}{$\begin{array}{l}\text { Size of Earthquake } \\
\text { (Magnitude) }\end{array}$}} & \multirow{4}{*}{$\begin{array}{l}\text { Expected } \\
\text { MMI }\end{array}$} & \multicolumn{5}{|c|}{ Standardized Damage States } \\
\hline & & & \multirow{3}{*}{$\begin{array}{r}\text { A } \\
\text { None }\end{array}$} & \multirow{3}{*}{$\begin{array}{r}\text { B } \\
\text { Slight }\end{array}$} & \multirow{3}{*}{$\begin{array}{r}\mathrm{C} \\
\text { Moderate }\end{array}$} & \multirow{3}{*}{$\begin{array}{r}\mathrm{D} \\
\text { Extensive }\end{array}$} & \multirow{3}{*}{$\begin{array}{r}\mathrm{E} \\
\text { Complete }\end{array}$} \\
\hline $6.0-6.5$ & $7.5-8.0$ & & & & & & \\
\hline \multicolumn{2}{|c|}{ Distance to Fault } & & & & & & \\
\hline $30 \mathrm{mi}$ & $50 \mathrm{mi}$ & VII & $40-60$ & $20-40$ & $10-20$ & $2-10$ & $<1$ \\
\hline $5 \mathrm{mi}$ & $40 \mathrm{mi}$ & VIII & $15-25$ & $15-25$ & $20-30$ & $25-35$ & $2-10$ \\
\hline $1 \mathrm{mi}$ & $30 \mathrm{mi}$ & IX & $2-10$ & $5-15$ & $25-35$ & $40-60$ & $5-15$ \\
\hline- & $3 \mathrm{mi}$ & $\mathrm{X}$ & $<1$ & $2-10$ & $10-20$ & $50-70$ & $15-25$ \\
\hline
\end{tabular}

Source: Expected Seismic Performance of Buildings, EERI.

has very good descriptions of the housing stock and estimated damage of different types due to different earthquake (MMI) intensities. In particular, they report that the housing stock in the bay area consists of $93 \%$ of woodframed structures. Structures are also classified by the number of stories. In the report one can find graphs conveying (approximately) the information in Table 6

Table 6: Per Cent Uninhabitable wooden one to three storied dwellings by intensity, type of structure and age

\begin{tabular}{|c|c|c|c|c|}
\hline Intensity & VII & VIII & IX & X \\
\hline Multi-family (pre-1940) & 1 & 14 & 60 & 81 \\
\hline Multi-family (post-1940) & 1 & 16 & 24 & 43 \\
\hline Single-family (pre-1940) & 0 & 3 & 7 & 10 \\
\hline Single-family (post-1940) & 0 & 0 & 1 & 3 \\
\hline
\end{tabular}

Source: Author's tabulation of graphs in ABAG report.

Together, these two reports provide enough information to construct a reasonable calibration of the estimated damage caused by earthquakes of different magnitudes. The way this is reflected in the simulation is by allocating households to different building structures using census data. Unfortunately, the census data does not contain sufficiently detailed descriptions 
on the structural properties of the housing units where the interviewee lives, but it does contain information on the total number of housing units in the building structure where s/he lives, and on the age of that structure. Correspondingly, households in CARDs are allocated to different building structures and risk groups as follows:

- Rich households $\rightarrow$ Single-family post 1970 wood-frame (risk group $\mathrm{A} 0$ )

- Poor households in owner occupied housing $\rightarrow$ Single-family post or pre 1970 wood-frame (A1 or A0) ${ }^{11}$

- Poor households in rented one-unit structure $\rightarrow$ Single-family post or pre 1970 wood-frame (A1 or A0)

- Poor households in rented two-four unit structure $\rightarrow$ Multi-family post or pre 1970 wood-frame (B1 or B0)

- Poor households in rented five plus unit structure $\rightarrow 20$-40 unit apartment building (post or pre 1970) (C1 or C0)

The number of wood frame structures damaged is calibrated from the ABAG data, and the number of apartment buildings with the EERI data. Note that I have taken a rather unorthodox cutoff date for old versus new buildings. This is because I have found that a substantial amount of awareness was created after the 1971 San Fernando earthquake and some substantial legislation was passed closely thereafter concerning earthquake damage to buildings; in particular, the Seismic Safety Commission was created in 1974, and the 1972 Fault Zoning Act, and the 1972 Hospital Safety Act were passed. Hence I feel that date to be a more significant classification date. The pre 1970 housing stock is allocated proportionately among poor households in rented homes.

With this data I calibrate the damage caused by an earthquake. As we saw above, the CARDs have a combined area that represents $8 \%$ of the total area of all the subdivisions that are at risk (both medium and high risk), and the probability that a magnitude $7.5+$ earthquake damages a densely populated area seems, from past experience, not to be proportional to the land surface. So, I decided to make the probability $32 \%$. Nevertheless,

\footnotetext{
${ }^{11}$ There are enough 'rich' households to occupy all the post-1970 owner occupied homes so I allocate all post-1970 homes to the 'richer' households for lack of data on the income distribution of older and newer buildings.
} 
I will keep the probability that it hits Los Angeles rather than San Francisco proportional to their relative areas, so that an earthquake that hits a densely populated area is one and a half times more likely to hit L.A. than San Francisco (the probabilities are .6 and .4). Once the earthquake hits a densely populated area, the damage it creates is geographically distributed into three zones: the area at the epicenter (MMI X) is defined as a circle with a 3 miles radius; those near the epicenter (MMI IX), everybody who lives in the same area (San Francisco or Los Angeles) ${ }^{12}$; and everybody else (MMI I- no damage). The average population density (2,494 for L.A., 1,769 for the Bay) is used to determine the number of homes at the epicenter. The different risk groups (A0-C1) are damaged in proportion to their number, and each home faces one of two possible consequences: no damage or complete damage. These have probabilities given in Table 7 .

Table 7: Probability of damage per class (in \%)

\begin{tabular}{|c|c|c|c|c|c|c|}
\hline & A0 & A1 & B0 & B1 & C0 & C1 \\
\hline X & 3 & 10 & 43 & 81 & 25 & 80 \\
\hline IX & 1 & 7 & 14 & 60 & 10 & 60 \\
\hline VIII & 0 & 3 & 16 & 14 & 5 & 35 \\
\hline VII & 0 & 0 & 1 & 1 & 1 & 10 \\
\hline
\end{tabular}

Table 8: Population per class (000s)

\begin{tabular}{|c|c|c|c|c|c|c|c|c|c|}
\hline & RA0 & RA1 & PA0 & PA1 & PB0 & PB1 & PC0 & PC1 & Total \\
\hline At risk (L.A.) & 612 & 649 & 207 & 1,058 & 122 & 195 & 432 & 692 & 3,967 \\
\hline Proportion & 0.15 & 0.16 & 0.05 & 0.27 & 0.03 & 0.05 & 0.11 & 0.18 & 1 \\
\hline At risk (S.F.) & 347 & 399 & 87 & 439 & 69 & 110 & 176 & 282 & 1,910 \\
\hline Proportion & 0.18 & 0.21 & 0.05 & 0.23 & 0.04 & 0.06 & 0.09 & 0.15 & 1 \\
\hline Total & 959 & 1,048 & 294 & 1,497 & 191 & 305 & 609 & 974 & 5,877 \\
\hline
\end{tabular}

Combining Tables 7 and 8 I obtain an estimate of the number of homes that will be damaged in each class (Table 9).

\footnotetext{
${ }^{12}$ This corresponds to those within a 30 mile radius, as described in Tables 4 and 5 .
} 
Table 9: Number of homes damaged by "The Big One"

\begin{tabular}{|c|c|c|c|c|c|c|c|c|c|}
\hline & RA0 & RA1 & PA0 & PA1 & PB0 & PB1 & PC0 & PC1 & Total \\
\hline S.F. & 3,653 & 28,275 & 919 & 31,046 & 10,148 & 66,623 & 18,339 & 170,898 & 329,901 \\
\hline L.A. & 6,338 & 45,758 & 2,145 & 74,615 & 17,681 & 117,676 & 44,382 & 417,512 & 726,107 \\
\hline
\end{tabular}

The final step in the estimation of damage is to estimate the economic effect of the destruction of the home. This is done by imputing surface areas to homes in different structures (A,B and C). Using data from the Constructor's Pricing Guide 1997 and the BNi Building News; Square Foot 1996 Costbook $^{13}$, I define

- Rich homes of class A: average two story home of custom quality construction with $2,800 \mathrm{sq} f \mathrm{ft}$ and a replacement cost of $\$ 72.40$ per sq ft, which amounts to a $\$ 202,720$ cost.

- Poor homes of class A: average one-and-a-half stories home of average quality construction with $1,800 \mathrm{sq}$ ft and a replacement cost of $\$ 63.85$ per sq ft, which amounts to a $\$ 114,930$ cost.

- Poor homes of class B: one half of an average two story home of average construction with $2,000 \mathrm{sq} \mathrm{ft}$ and a replacement cost of $\$ 63.55$ per sq $\mathrm{ft}$, which amounts to a $\$ 127,100$ [\$63,550 per unit] cost.

- Poor homes of class C: unit rental in an apartment building of average quality (steel frame) with $1,000 \mathrm{sq} \mathrm{ft}$ and a replacement cost of $\$ 73.19$ per sq ft, which amounts to a $\$ 73,190$ per unit cost.

This implies an estimated damage of: 726,107 homes (\%18.3 of the housing stock) at a cost of $\$ 61,790,898,583$ for Los Angeles, and 329,901 (\% 17.3 of the housing stock) at $\$ 28,875,304,435$ in the Bay Area. This estimate is an underestimate of the number of damaged homes as there will be very many partially damaged homes. On the other hand, the cost of a damaged home has been exaggerated to cover full reconstruction; on average it seems like a good approximation ${ }^{14}$.

\footnotetext{
${ }^{13}$ The cost estimations which are the basis for these estimates are shown in Appendix 7.2

${ }^{14}$ Also, note that reconstructing such a large percentage of the housing stock at the same time would cause a huge excess demand for construction services which would drive reconstruction costs much higher. Unfortunately, in order to model that aspect one would need to include a housing market which I leave for future research.
} 
Having defined the agent's preferences and endowments, and calibrated the statistical distribution of large damaging earthquakes, together with the economic damage they will cause, we can now see what the equilibrium will look like. Before we do, one last caveat needs to be added: the damage to homes is much greater than the household's per quarter income $(17,500$ for the rich and 7,500 for the poor). In a simple exchange economy such as this the only way to represent the corresponding loss in wealth is to extend the damage to future periods. Correspondingly, rich agents (RA) will lose 15,592 units of consumption during 13 periods, poor agents in single-family homes (PA) will lose 6,760 units for 17 periods, poor agents in multi-family homes (PB) will lose 4,885 over 13 periods, and poor agents in apartment buildings (PC) 4,885 for 15 periods. The allocation of cost to apartment dwellers is somewhat contrived as they usually rent the apartments and hence would not bear the brunt of reconstructing the building. On the other hand, someone will bear that cost and this model is too simple to deal with issues of ownership versus rent (which ideally should be an endogenous decision). I have included these costs because I wish to calibrate the effect of the damage to residential housing stock so when one interprets the resulting trades for apartment dwellers one will have to take these issues into account.

\section{The Arrow-Debreu Equilibrium}

In this section I will solve the above model for the Walrasian equilibrium prices and consumptions.

The model presented here is a special one within the class of those developed in Penalva[1997a, 1997b]. One can describe prices and consumptions using a countable number of relevant events. The aggregate endowment at date event pair, $\left(t, a_{t}\right)$, is $w\left(t, a_{t}\right)=\sum_{i \in I} w_{i}\left(t, a_{t}\right)$. The date event $(0, \Omega)$ will be referred to only by the date: $(0)$. The sums $\sum_{t=0}^{\infty}$ and $\sum_{a_{t} \in f_{t}}$ will be replaced by the shorter notation: $\sum_{t}$ and $\sum_{a_{t}}$. Agent $i$ 's net trade at date event pair $\left(t, a_{t}\right)$ is denoted $\Delta x_{i}\left(t, a_{t}\right):=x_{i}\left(t, a_{t}\right)-w_{i}\left(t, a_{t}\right)$. Sometimes it will be useful to refer to the whole of the agent's consumption or endowment vectors. The vector $x \in L$ is related to the state event representation in the following manner:

$$
x=\sum_{t} \sum_{a_{t}} \mathbf{1}_{\left(t, a_{t}\right)} x\left(t, a_{t}\right),
$$

where $\mathbf{1}_{\left(t, a_{t}\right)}$ refers to the indicator function for the date-event pair $\left(t, a_{t}\right)$. Given the nature of the dual, a price functional, $p \in L^{*}$ can be similarly 
represented

$$
p=\sum_{t} \sum_{a_{t}} \mathbf{1}_{\left(t, a_{t}\right)} P\left(a_{t}\right) \pi\left(t, a_{t}\right)
$$

Having introduced the necessary notation, I will start with the individual's problem. Every agent solves the problem

$$
\begin{aligned}
\max _{x_{i}} & E_{P}\left[\sum_{t=0}^{\infty} \beta^{t} \frac{x(t)^{1-\rho}}{1-\rho}\right] \\
\text { subject to } & \sum_{t=0}^{\infty} \sum_{a_{t} \in f_{t}} P\left(a_{t}\right) \pi\left(t, a_{t}\right) \Delta x_{i}\left(t, a_{t}\right)=0
\end{aligned}
$$

where $\pi\left(t, a_{t}\right)$ is the relative price of consumption at date-event pair $\left(t, a_{t}\right)$ relative to consumption at date $0^{15}$. Given the concave and differentiable nature of the problem we can obtain an expression for the optimal consumption at date-event pair $\left(t, a_{t}\right)$ :

$$
x_{i}\left(t, a_{t}\right)=x_{i}(0)\left[\frac{P\left(a_{t}\right) \pi\left(t, a_{t}\right)}{P\left(a_{t}\right) \beta^{t}}\right]^{\frac{-1}{\rho}},
$$

where $P\left(a_{t}\right)$ is the probability measure of event $a_{t} \in f_{t}$. Using the equilibrium market clearing condition

$$
\begin{aligned}
w\left(t, a_{t}\right) & =\int_{I} x_{i}\left(t, a_{t}\right) \\
& =\left[\frac{\pi\left(t, a_{t}\right)}{\beta^{t}}\right]^{-\rho} \int_{I} x_{i}(0)
\end{aligned}
$$

we obtain an expression for the relative price of consumption at date-event $\left(t, a_{t}\right)$.

$$
\pi\left(t, a_{t}\right)=\beta^{t}\left[\frac{w(0)}{w\left(t, a_{t}\right)}\right]^{\rho}
$$

Using this in the agent's optimal consumption we obtain

$$
x_{i}\left(t, a_{t}\right)=x_{i}(0)\left[\frac{\pi\left(t, a_{t}\right)}{\beta^{t}}\right]^{-\frac{1}{\rho}}=x_{i}(0) \frac{w\left(t, a_{t}\right)}{w(0)}
$$

\footnotetext{
${ }^{15}$ This implicitly normalizes the representation of the price vector using $\pi(0)=1$.
} 
Also, inserting for price in the budget equation we can obtain an analytical expression of the agent's optimal consumption as a function of primitives

$$
\begin{aligned}
p \cdot w_{i} & =\sum_{t} \sum_{a_{t}} P\left(a_{t}\right) \pi\left(t, a_{t}\right) x_{i}\left(t, a_{t}\right) \\
& =\sum_{t} \sum_{a_{t}} P\left(a_{t}\right) \pi\left(t, a_{t}\right) x_{i}(0) \frac{w\left(t, a_{t}\right)}{w(0)} \\
& =x_{i}(0) \sum_{t} \sum_{a_{t}} P\left(a_{t}\right) \beta^{t}\left(\frac{w\left(t, a_{t}\right)}{w(0)}\right)^{1-\rho} \\
& =x_{i}(0) \sum_{t} \beta^{t} E_{P}\left[\left(\frac{w\left(t, a_{t}\right)}{w(0)}\right)^{1-\rho}\right]
\end{aligned}
$$

so that

$$
x_{i}(0)=\frac{p \cdot w_{i}}{\sum_{t} \beta^{t} w(0)^{-1+\rho} E_{P}\left[w\left(t, a_{t}\right)^{1-\rho}\right]}
$$

where $p \cdot w_{i}$ can be computed using equation (1).

As I have assumed that agents' preferences are strictly concave, following the result in the theoretical chapter, agents' consumption allocations are functions of the aggregate endowment. This allows me to describe agents' consumption by the fraction of endowment that they represent. In addition, my choice of preferences satisfies the stronger assumptions of Mace[1991], Townsend[1993, 1994] so that consumption reflects 'perfect risk-sharing': the consumption of each agent represents a constant, time-invariant fraction of the aggregate endowment.

Prices, as we have seen above, can be described analytically. Consumptions, on the other hand, require one to compute the value of each agent's endowment. For that one needs the probabilities of different states at different points in time conditional on the histories. The probabilistic description does not allow for a simple analytical description of such probabilities, hence the need to resort to a computer simulation. Using the paths simulated using the distribution of interarrival times of section 3.1.2, one can compute the date zero value of the agent's endowments, and use them to calculate agents' net trades. The net trades at date zero per type at risk are given in Table 10. Those not at risk have net trades of 0.88 (rich households) and 0.44 (poor households).

One thing to note is that the value of agents' endowments has been computed as if the economy was a type economy with an infinite number of agents. This is done for ease of computation and implies that the results 
Table 10: Date Zero Equilibrium Net Trades

\begin{tabular}{|c|c|c|c|c|c|c|c|c|}
\hline$\Delta_{w} x_{i}$ & RA0 & RA1 & PA0 & PA1 & B0 & B1 & C0 & C1 \\
\hline L.A. & -0.26 & -8.90 & -0.28 & -5.10 & -6.00 & -27.00 & -4.80 & -31.00 \\
\hline S.F. & 0.47 & -3.80 & 0.12 & -2.30 & -2.70 & -13.00 & -2.10 & -15.00 \\
\hline
\end{tabular}

Source: Author's Simulation.

presented are for the average agent of each type - all agents having been treated identically. As we can see from Table 10, the households who live in the rest of the United States receive a premium in order to share their consumption when an earthquake occurs. This is also true of some households who are at relatively low risk: those living in San Francisco and in new single-family, wooden-frame houses. The rest of the households at risk give up some of their endowments in the non-accident states in order to share consumption later on. The households at greatest risk, those living in old apartment buildings and multi-family homes, are the ones who have to give up most. Notably, even then the households give up at most 0.4 per cent of their quarterly endowment (without taking into account earthquake damage). The contrast between those living in Los Angeles and San Francisco is notable in that those living in Los Angeles pay a higher premium than the corresponding households in San Francisco. This is not surprising because if an earthquake hits, it is more likely to hit in Los Angeles than in San Francisco (the probabilities are 0.6 and 0.4 respectively) but even this difference in probability is not sufficient to justify the difference in consumption. The greater extent of destruction associated with Los Angeles quakes means that Los Angeles residents need to give up more consumption than those in the Bay Area even if one takes into account the differences in probabilities.

\section{$5 \quad$ Financial Prices}

Now that we have seen how agents would adjust their consumptions to deal with the risk of earthquakes one needs to consider how these beneficial consumption exchanges can be implemented. The main institution for risk sharing in modern economies is through insurance markets. Can actual markets deal with these earthquakes? How would they? The answer, as is shown in Penalva[1997b], is through standard insurance contracts and trading in financial securities such as bonds and insurance derivatives 
(catastrophe bonds, for example). This economy has a two risk classes, the class of Northern California earthquakes and that of Southern California earthquakes. From Penalva[1997b] and the fact that each agent's private endowment is affected only by one kind of earthquakes (the Northern or the Southern California ones), we know that every agent's optimal portfolio can be fully characterized by trading in a bond, a single personalized insurance contract, and two derivatives on the aggregate endowment. The most suitable derivatives in this context are catastrophe bonds. Catastrophe bonds are a new kind of security, similar to corporate bonds. They essentially pay a premium over standard bonds but if a certain catastrophe occurs the holder may lose part or all of the principal. We will see them in more detail below.

In this model there is an catastrophe bond for earthquakes in Los Angeles and one for earthquakes in San Francisco. These bonds are redundant securities, as they can be constructed as a weighted average of the individual insurance contracts issued in their respective areas. They are traded as a means to diversify the aggregate risk to the economy. In this section I will show what the implications of the state-contingent equilibrium prices are for security prices and the cost of insurance contracts and catastrophe bonds.

\section{$5.1 \quad$ Interest Rates}

The first security that needs to be priced is the riskless bond, the security managing intertemporal flows. The model I have constructed measures intervals between consumption dates as quarters. Conveniently, the U.S. government issues 3-month bonds, or T-bills. This model is not sophisticated enough to capture the complexities of actual T-bill prices so the relationship between the interest rates in this model and actual interest rates is only illustrative of what models of this type could capture (and have, see for example the classic paper by Mehra and Prescott [1985] analyzing the returns on government bonds vis-a-vis returns from stocks). In this model, the bond is a security that pays one unit of consumption for sure at the next consumption date. Naturally, its price is given by

$$
B(t):=\frac{1}{1+r(t)}=\frac{E_{P}\left[\pi(t+1) \mid \mathcal{F}_{t}\right]}{\pi(t)},
$$

which at a given date-event $\left(t, a_{t}\right)$ is given by

$$
B\left(t, a_{t}\right)=\sum_{\substack{a_{t+1} \subset a_{t} \\ a_{t+1} \in f_{t+1}}} \frac{P\left(a_{t+1} \mid a_{t}\right) \pi\left(t+1, a_{t+1}\right)}{\pi\left(t, a_{t}\right)}
$$




$$
\begin{aligned}
& =\sum_{\substack{a_{t+1} \subset a_{t} \\
a_{t+1} \in f_{t+1}}} \frac{P\left(a_{t+1} \mid a_{t}\right) \beta^{t+1} w(0)^{\rho} w\left(t+1, a_{t+1}\right)^{-\rho}}{\beta^{t} w(0)^{\rho} w\left(t, a_{t}\right)^{-\rho}} \\
& =\beta \sum_{\substack{a_{t+1} \subset a_{t} \\
a_{t+1} \in f_{t+1}}} P\left(a_{t+1} \mid a_{t}\right)\left(\frac{w\left(t, a_{t}\right)}{w\left(t+1, a_{t+1}\right)}\right)^{\rho}
\end{aligned}
$$

The resulting return for the first year is a quarterly interest rate of $1.01 \%$ (and a yearly interest rate of $4.1 \%$ ). The most interesting aspect of this model is that it allows us to calculate prices for insurance contracts and how agents will trade on those contracts.

\subsection{Insurance Contracts}

An insurance contract against earthquakes establishes that the insurance company, which is usually the issuer of the contract, will pay the holder of the contract conditional on the individual's home being damaged by an earthquake. Usually, the contract covers the home for a year and it specifies a deductible and limits on coverage which can make the contract quite complex. The approach I take here is to define an insurance contract as a claim payable conditional on an accident occurring to a particular household (home). These claims are issued in $\$$ per $\$ 1,000$ of coverage $^{16}$. Agents can buy and sell as many of these contracts as they wish, and the contracts will be traded at the market price (the price derived from the contingent-commodity market equilibrium, which is also arbitrage-free). Insurance contracts are issued on a yearly basis. They are also personalized commodities/securities, as each says:

The holder of this contract is entitled to 1,000 units of consumption if ____'s home is damaged by an earthquake within one year of the date of issue of this contract.

The blank specifies the agent whose home is being insured. Hence, there are $5,876,707$ potential insurance contracts, i.e., one for every household living in a CARD. One of the most elegant aspects of this model is, as we shall see later, that agents need to trade in at most four securities to attain their optimal consumption allocations - a much more manageable number than 5.9 million!.

\footnotetext{
${ }^{16}$ Of course, there is no actual money in the economy so when I talk about a $\$$ I mean one unit of the consumption commodity. The appropriate date-event should be clear from the context.
} 
The insurance contract prices issued for a whole year (four quarters) are displayed in Table 11. Insurance contracts for most types follow a quite predictable pattern, increasing with the likelihood of damage and greater for those in the Los Angeles basin and for the larger earthquake.

Table 11: One Year Insurance Contract Prices $(7.5+, \$$ per $\$ 1,000$ of coverage)

\begin{tabular}{|c|c|c|}
\hline Agent Type & Los Angeles & San Francisco \\
\hline RA0 & 0.018 & 0.013 \\
\hline RA1 & 0.13 & 0.08 \\
\hline PA0 & 0.018 & 0.012 \\
\hline PA1 & 0.13 & 0.08 \\
\hline PB0 & 0.26 & 0.17 \\
\hline PB1 & 1.07 & 0.72 \\
\hline PC0 & 0.18 & 0.12 \\
\hline PC1 & 1.07 & 0.72 \\
\hline
\end{tabular}

Source: Author's Simulation.

The conclusion is that insurance prices follow the pattern described by the CEA: higher prices in riskier areas and for homes that are more likely to be damaged during an earthquake, but the price of coverage is one order of magnitude lower than that proposed by the CEA. As a direct comparison, the average price of coverage for households living in CARDs ${ }^{17}$ is 29 cents per thousand dollars of coverage (without deductible), while that proposed by the CEA is $\$ 3.29$ per thousand with a $15 \%$ deductible. The estimated insurance prices may seem very small so let us check by doing a simple backof-the-envelope calculation: the estimated cost of damage is $\$ 60$ billion in Los Angeles and $\$ 30$ billion in San Francisco. The big one comes in once every one hundred years, and when it does I have given it a 40 per cent chance of hitting a densely populated area; with 0.6 probability it will hit L.A. and with 0.4 San Francisco; hence, the expected cost is $60 * 0.01 * 0.32 *$ $0.6+30 * 0.01 * 0.32 * 0.4=0.1536$ or $\$ 154$ million, which discounted at 4 per cent is $\$ 148$ million, which is essentially what is paid out in insurance premia using those in Table 11. The average price of insurance against a

\footnotetext{
${ }^{17}$ This is an overestimate because it uses just the households living in CARDs, not the whole of California.
} 
major catastrophic earthquake is lower than that proposed by the $\mathrm{CEA}^{18}$.

\subsection{Pricing Catastrophe Bonds}

The last type of security traded is catastrophe bonds. Catastrophe bonds are issued by insurance and reinsurance companies. Swiss Re (reinsurance) has issued $\$ 137$ million bonds on a East Coast earthquake while United Services Automobile Association (USAA, home and auto insurance) has issued \$477 million bonds on East Coast hurricanes. These bonds are rated as between Aaa and Baa2 by rating agencies (Fitch Investors Service, Standard \& Poor's, Moody's Investors Service, and Duff \& Phelps Credit Rating Company) as they would any other bond, and pay between $11.4 \%$ and $8.41 \%$ (as of June 5, 1997). They are structured in a similar fashion to reinsurance contracts: they pay a premium over riskless bonds but if the insurance (or reinsurance) company has to pay claims above a certain threshold because a catastrophe occurs then the holder of the bond has to pay the company, which in the case of the bond means that the holder loses part or all of the principal.

In my model, catastrophe bonds are structured as follows: the bonds are issued yearly (i.e. for four periods); at the expiration date they pay: the yearly riskless interest rate plus 4 per cent $(1+r+0.04)$ if there is no earthquake, half of the principal if there is a single earthquake $(1 / 2)$, and nothing if there are two or more earthquakes. There are two kinds of bonds, one for Los Angeles and one for the Bay Area, and they pay conditional on accidents on their area; if two earthquakes hit San Francisco in the same year and none in Los Angeles, the Los Angeles bond pays $1+r+0.04$.

The competitive price for the Los Angeles catastrophe bond is $\$ 1.03736$ and for the San Francisco/Bay Area bond \$1.03771, which implies that the competitive mark-up over the company's normal corporate bonds should be around 0.25 of one per cent, not 4 per cent. The issuers of catastrophe bonds did announce that these bonds carry an excess premium which is intended to compensate investors for the novelty of the product, but the extra premium is about $3.7 \%$ above the competitive price -quite a substantial amount- so one would expect these bonds to be in high demand.

\footnotetext{
${ }^{18}$ There is one aspect of the calculations in this paper that needs to be taken into account: the calculations are done for a very large catastrophic earthquake, it does not include the damage from more frequent and less damaging earthquakes, in particular, it does not include coverage for such earthquakes as the Northridge or Loma Prieta earthquakes. Nevertheless, I am quite confident that including these kinds of earthquake will not bring the premium substantially closer to the CEA proposal.
} 
As shown in Penalva[1997b], trading in these bonds, together with the Tbill and private insurance contracts suffices for agents to attain their optimal net trades.

\section{Conclusion}

I have constructed a simple exchange model of the California economy using the hybrid time structure presented in Penalva[1997a, 1997b] and used it to analyze a competitive market for earthquake insurance for residential homes. I have restricted attention to catastrophic earthquakes in densely populated areas and estimated the likelihood and damage caused by an earthquake. This I have done using data on past earthquakes, by estimating damage caused by large earthquakes to existing building structures, and by looking at the replacement value of the homes in those structures. I have used the model to compute agents' optimal consumption patterns, and prices for insurance contracts and catastrophe bonds.

The conclusions from this analysis are that agents optimally diversify their idiosyncratic risk by sharing their endowments; this can be implemented as a security market equilibrium in which agents at risk buy insurance contracts to protect their homes and trade in the riskless bond and in catastrophe bonds to share in aggregate uncertainty; the implied prices for insurance contracts are one order of magnitude lower than those presently being proposed by the California Earthquake Authority, even for contracts that offer full coverage as opposed to those proposed by the CEA that include a $15 \%$ deductible. Also, agents will purchase full coverage at the competitive prices. Furthermore, the implied prices for catastrophe bonds suggest that catastrophe bonds currently being traded incorporate a substantial premium above competitive prices (a premium of $3.7 \%$ ).

These results are suggestive of the impact of the highly regulated environment surrounding current insurance markets and the possible benefits from introducing a larger degree of market competitiveness. It also suggests that the introduction of catastrophe bonds is a very important financial innovation that fulfills an essential role for diversifying and spreading the financial burden of insuring individual homes against major natural disasters. On the other hand, the model presented here is a very simple model that would benefit from additional research, both in terms of constructing a more sophisticated description of the U.S. economy as well as from a more complete description of the housing market. Nevertheless, the differences between security prices in this model and those taken from actual markets are 
sufficiently large to raise concerns about the efficiency of current insurance markets and the legal framework within which they operate. 


\section{Appendix A: Data}

\subsection{California Earthquakes}

The following table has been taken from California Geology, February 1986 (California Department of Conservation), Earthquake History of the U.S., 1982 (U.S. Department of Commerce and Department of Interior), State of California, Office of Emergency Services records, the California Seismic Safety Comission Website:

http://www.seismic.ca.gov/sscsigeq.htm

Number of major earthquakes (1947-present).................28

Average Damage ............................ 725 (Jan1992\$ Million)

Seventy-fifth Percentile .....................55 (Jan1992\$ Million) 


\subsection{Replacement Cost Tables}

The following tables outline the average living area and per square foot cost of different classes of construction for different building configurations. All estimates are for wood sliding frames, except the one story economy home which has a stucco wood frame.

Table 12: Average Economy Home

\begin{tabular}{lccc} 
Building Configuration & Average Surface Area & Cost per square foot & Total \\
\hline One story & $1,200 \mathrm{sq} \mathrm{ft}$ & $\$ 54.55$ & $\$ 65,460$ \\
One-and-a-half stories & $1,600 \mathrm{sq} \mathrm{ft}$ & $\$ 51.80$ & $\$ 82,880$ \\
Two stories & $2,000 \mathrm{sq} \mathrm{ft}$ & $\$ 50.65$ & $\$ 101,300$ \\
Tri-level building & $2,400 \mathrm{sq} \mathrm{ft}$ & $\$ 42.95$ & $\$ 103,080$
\end{tabular}

Table 13: Average Home

Building Configuration Average Surface Area Cost per square foot Total

\begin{tabular}{llll}
\hline One story & $1,600 \mathrm{sq} \mathrm{ft}$ & $\$ 64.10$ & $\$ 102,560$ \\
One-and-a-half stories & $1,800 \mathrm{sq} \mathrm{ft}$ & $\$ 63.85$ & $\$ 114,930$ \\
Two stories & $2,000 \mathrm{sq} \mathrm{ft}$ & $\$ 63.55$ & $\$ 127,100$ \\
Tri-level building & $2,400 \mathrm{sq} \mathrm{ft}$ & $\$ 56.35$ & $\$ 135,240$
\end{tabular}


Table 14: Average Custom Home

\begin{tabular}{lccc} 
Building Configuration & Average Surface Area & Cost per square foot & Total \\
\hline One story & $2,400 \mathrm{sq} \mathrm{ft}$ & $\$ 72.30$ & $\$ 173,520$ \\
One-and-a-half stories & $2,800 \mathrm{sq} \mathrm{ft}$ & $\$ 70.35$ & $\$ 196,980$ \\
Two stories & $2,800 \mathrm{sq} \mathrm{ft}$ & $\$ 72.40$ & $\$ 202,720$ \\
Tri-level building & $3,200 \mathrm{sq} \mathrm{ft}$ & $\$ 65.40$ & $\$ 209,280$
\end{tabular}

Table 15: Average Luxury Home

\begin{tabular}{lccc} 
Building Configuration & Average Surface Area & Cost per square foot & Total \\
\hline One story & $2,800 \mathrm{sq} \mathrm{ft}$ & $\$ 86.90$ & $\$ 243,320$ \\
One-and-a-half stories & $2,800 \mathrm{sq} \mathrm{ft}$ & $\$ 80.75$ & $\$ 226,100$ \\
Two stories & $3,200 \mathrm{sq} \mathrm{ft}$ & $\$ 78.40$ & $\$ 250,880$ \\
Tri-level building & $3,600 \mathrm{sq} \mathrm{ft}$ & $\$ 71.55$ & $\$ 257,580$
\end{tabular}

To estimate the construction costs for apartments I use the following to examples taken from the BNi Building News 1996 Costbook:

1. New construction of an apartment building. Limited budget and small downtown site. 150 rental units. Rigid Steel Frame. Habitable surface: $115,900 \mathrm{sq}$ ft. Construction cost estimate: $\$ 63.76$ per sq ft; $\$ 7,390,300$ total. Per unit: $773 \mathrm{sq} \mathrm{ft}$ habitable space at a cost of $\$ 49,269$.

2. New construction of apartment housing for the elderly. Attractive building. 200 units. Steel frame. Habitable surface: 144,285 sq ft. Construction cost estimate: $\$ 73.19$ per sq ft; $\$ 10,560,200$. Per unit: 721 sq ft habitable space at a cost of $\$ 52,801$. 


\section{Appendix B: Modified Mercalli Scale}

I. Not felt.

II. Felt by persons at rest, on upper floors, or favorably placed.

III. Felt indoors. Hanging objects swing. Vibration like passing of light trucks.

IV. Hanging objects swing. Windows, doors, dishes rattle. Vibration like passing of heavy truck or jolt like a heavy ball striking the walls.

V. Felt outdoors, sleepers wakened. Liquids disturbed or spilled. Small unstable objects displaced or upset. Pictures move.

VI. Felt by all. Persons walk unsteadily. Windows dishes and glasses broken. Pictures off walls. Furniture moved or overturned. Weal plaster and masonry cracked.

VII. Difficult to stand. Noticed by car drivers. Furniture broken. Damage to weak masonry, some cracks in ordinary masonry. Weak chimneys broken at roof line. Fall of plaster, loose bricks, stones, tiles and unbrace parapets.

VIII. Steering of cars affected. Damage to ordinary masonry, partial collapse. Twisting, fall of chimneys, factory stacks, monuments, towers, elevated tanks. Frame houses moved on foundations if not bolted down; loose panel walls thrown out. Cracks in wet ground and on steep slopes.

IX. General Panic. Poor masonry destroyed, ordinary masonry heavily damaged, sometimes with complete collapse, reinforced masonry damaged, general damage to foundations. Frame structures, if not bolted, shifted off foundations. Frames racked. Underground pipes broken. Conspicuous cracks in ground. Liquefaction in areas of sand and mud.

X. Most masonry and frame structures destroyed. Some well-built wooden structures and bridges destroyed. Serious damage to dams, dikes, embankments. Large landslides. Rails bent slightly.

XI. Rails bent greatly. Underground pipelines completely out of service.

XII. Damage nearly total. Large rock masses displaced. 


\section{References}

[1] ABAG [1997]. Earthquake and Housing Impacts.

[2] BNi Building News: Square Foot 1996 Costbook. 6th ed. BNi Publications

[3] Bremaud, P. [1981]. Point Processes and Queues: Martingale Dynamics. Springer-Verlag. New York.

[4] Constructor's Pricing Guide: Residential Square Foot Costs 1997. R.S. Means Co., Inc.

[5] Cooley, Thomas F. (ed.) [1995]. Frontiers of Business Cycle Research. Princeton University Press. Princeton, New Jersey.

[6] Diamond, P. [1967]. "The role of a Stock Market in a General Equilibrium Model with Technological Uncertainty." American Economic Review 57: 759-776.

[7] EERI Ad Hoc Committee on Seismic Performance [1994]. Expected Seismic Performance of Buildings. Earthquake Engineering Research Institute.

[8] Helbling, C.P., G. Fallegger, and D. Hill [1996]. Rethinking Risk Financing. Swiss Reinsurance Company.

[9] Iacopi, R.L. [1996]. Earthquake Country. Fisher Books. Arizona.

[10] Mehra, R. and E. Prescott [1985]. "The equity premium: A puzzle." in Journal of Monetary Economics 15: 145-162

[11] Penalva Zuasti, Jose S. [1997a] The Theory of Financial Insurance with an Application to Earthquakes and Catastrophe Bonds. PhD Thesis, UCLA.

[12] Penalva Zuasti, Jose S. [1997b]. "Risk-Sharing, Finance, and Hybrid Time: A Mutual Fund Theorem with Personalized Insurance Contracts." mimeo, UCLA.

[13] Townsend, Robert M. [1993]. The Medieval Village Economy. Princeton University Press. Princeton, New Jersey.

[14] Townsend, Robert M. [1994]. "Risk and Insurance in Village India," Econometrica 62 539-591. 
[15] Wilson, R. [1968]. "The Theory of Syndicates." Econometrica 36: 119132. 